\title{
Promoção da saúde escolar: uma construção dialógica de saberes com escolares
}

\author{
Promotion of school health: a dialogic construction of knowledge with school \\ Promoción de la salud escolar: una construcción dialógica del conocimiento con los escolares
}

Recebido: 30/12/2021 | Revisado: 04/01/2022 | Aceito: 07/01/2022 | Publicado: 11/01/2022

Tatiane Marinz de Souza Luquez

ORCID: https://orcid.org/0000-0001-8895-9950

Universidade Federal Fluminense, Brasil

E-mail: tatianemarinz@gmail.com

Vera Maria Saboia

ORCID: https://orcid.org/0000-0003-0382-5078 Universidade Federal Fluminense, Brasil E-mail: verasaboia@uol.com.br

Gabriela Oliveira Mayworm Teixeira ORCID: https://orcid.org/0000-0003-1903-7930 Universidade Federal Fluminense, Brasil E-mail: gabriela_mayworm@hotmail.com

Talita Marchióro de Lima Silva

ORCID: https://orcid.org/0000-0001-9750-3939 Universidade Federal Fluminense, Brasi talitamarchioro9900@gmail.com

Donizete Vago Daher

ORCID: https://orcid.org/0000-0001-6249-0808 Universidade Federal Fluminense, Brasil E-mail: donidaher@gmail.com

Lina Márcia Miguéis Berardinelli ORCID: https://orcid.org/0000-0002-9481-8414 Universidade do Estado do Rio de Janeiro, Brasil E-mail: linamigberardinelli@gmail.com

Rosane Cordeiro Burla de Aguiar ORCID: https://orcid.org/0000-0002-5734-3392 Universidade Federal Fluminense, Brasil E-mail: rcburla@yahoo.com.br

Crystiane Ribas Batista Ribeiro

ORCID: https://orcid.org/0000-0002-3026-8548 Universidade Federal Fluminense, Brasil E-mail: crystiane.ribas@gmail.com

\begin{abstract}
Resumo
Objetivo: compreender a concepção de discentes sobre prática educativa em saúde no ambiente escolar e desenvolver ações educativas em saúde com estudantes do ensino fundamental. Metodologia: estudo qualitativo, do tipo pesquisaação, desenvolvido com 24 educandos do $6^{\text {a }}$ ano do ensino fundamental de uma Escola Municipal de Niterói, Rio de Janeiro. Dados produzidos pela técnica World Café e submetidos à análise temática. Resultados: emergiram duas categorias: Concepção de saúde: a visão dos estudantes e Práticas educativas em saúde na escola: a demanda dos educandos. Os participantes correlacionaram saúde com prevenção de doenças. As demandas temáticas versaram sobre meio ambiente, desenvolvimento e higiene do corpo. Estratégias lúdicas e dinâmicas foram sugeridas para aprendizagem. Na fase ação, desenvolveram-se três práticas educativas a partir da demanda dos discentes, avaliadas positivamente pelos educandos. Considerações finais: a prática educativa em saúde com abordagem participativa sendo planejada e desenvolvida com o emprego de situações cotidianas e demandadas pelos participantes é um potente instrumento de promoção da saúde possibilitando a (re)construção dialógica de saberes com escolares.

Palavras-chave: Promoção da saúde; Educação em saúde; Serviços de saúde escolar; Prática de saúde pública; Saúde do adolescente.

Abstract

Objective: to understand the conception of students about health education practice in the school environment and to develop health education actions with elementary school students. Methodology: qualitative study, action-research type, developed with 24 students in the 6th year of elementary school at a Municipal School in Niterói, Rio de Janeiro. Data obtained by the World Café technique and analysis through thematic analysis. Results: two categories emerged: Concepts of health: a view of students and Educational practices in health at school: the demand of students. Participants correlated health with disease prevention. The thematic demands were about the environment,
\end{abstract}


development and hygiene of the body. Playful and dynamic strategies were suggested for learning. In the action phase, three educational practices were developed based on the demand of the students, which were positively evaluated by the students. Final considerations: the educational practice in health with a participative approach, being planned and developed with the use of everyday situations demanded by the participants, is a powerful instrument for health promotion, enabling the dialogic (re)construction of knowledge with students.

Keywords: Health promotion; Health education; School health services; Public health practice; Adolescent health.

\section{Resumen}

Objetivo: comprender la concepción de los estudiantes sobre la práctica de la educación para la salud en el ámbito escolar y desarrollar acciones de educación para la salud con los estudiantes de la escuela primaria. Metodología: estudio cualitativo, tipo investigación-acción, desarrollado con 24 alumnos de sexto año de la escuela primaria en una Escuela Municipal de Niterói, Rio de Janeiro. Datos obtenidos mediante la técnica World Café y análisis mediante análisis temático. Resultados: surgieron dos categorías: Conceptos de salud: una mirada de los estudiantes y Prácticas educativas en salud en la escuela: la demanda de los estudiantes. Los participantes correlacionaron la salud con la prevención de enfermedades. Las demandas temáticas fueron sobre el medio ambiente, el desarrollo y la higiene del cuerpo. Se sugirieron estrategias lúdicas y dinámicas para el aprendizaje. En la fase de acción, se desarrollaron tres prácticas educativas basadas en la demanda de los estudiantes, las cuales fueron evaluadas positivamente por los estudiantes. Consideraciones finales: la práctica educativa en salud con enfoque participativo, siendo planificada y desarrollada con el uso de situaciones cotidianas demandadas por los participantes, es un poderoso instrumento de promoción de la salud, posibilitando la (re) construcción dialógica del conocimiento con los estudiantes.

Palabras clave: Promoción de la salud; Educación en salud; Servicios de salud escolar; Práctica de salud pública; Salud del adolescente.

\section{Introdução}

A Organização Pan-Americana da Saúde (OPAS), em 1995, lançou a proposta das Escolas Promotoras de Saúde (EPS) na América, almejando mudanças no paradigma tradicional da saúde escolar e visando uma educação com práticas integradoras (Cavalcanti et al., 2015). Na América Latina, a saúde escolar como política pública envolve iniciativas municipais e nacionais com estratégias de promoção da saúde nas escolas (Casemiro et al., 2014). No Brasil, destaca-se o Programa Saúde na Escola (PSE), instituído em 2007, que propõe um trabalho integrado entre saúde e educação, na perspectiva de ampliar ações de saúde com estudantes da rede pública de ensino por meio da promoção e atenção à saúde, a partir do planejamento de ações, considerando o contexto escolar, social e demanda dos educandos (Chiari et al., 2018).

A comunidade escolar é um ambiente favorável para o desenvolvimento de ações de promoção da saúde, visto seu potencial para realização de ações coletivas, intersetoriais e participativas, que contribuem no processo de promoção da saúde de forma crítica e reflexiva. Promoção da saúde é um processo que objetiva ampliar as possibilidades de escolhas mais favoráveis e protagonizar a produção da própria saúde (Luquez et al., 2019). Nesse sentido, as práticas educativas em saúde nas escolas são determinantes, uma vez que ao desencadear discussões apresentam perspectivas em relação aos processos de saúde e fortalecem relações entre profissionais e educandos.

Tais perspectivas são cruciais no processo de adolescer, visto que a adolescência é caracterizada por mudanças biopsicossociais peculiares a cada ser, reorientando hábitos e comportamentos. Os adolescentes podem vivenciar novas experiências e significados que amparam a sua formação como um novo ser no mundo. Eles reconhecem a escola como ambiente propício ao relacionamento e à convivência com o outro e com o mundo, facilitada pela construção de valores e formação intelectual (Faial et al., 2016).

Entretanto, a permanência do enfoque biomédico no conceito de saúde mantém as ações educativas na forma de intervenções tradicionais preventivas, refletindo na prática educativa em saúde pontual, baseando-se apenas na informação técnica e objetivando mudanças de comportamento (Fontana, 2018). Os educadores, por sua vez, não costumam consultar a visão, necessidades e interesses dos educandos antes do desenvolvimento das ações educativas em saúde (Luquez, et al., 2019). Para Freire, a educação não acontece de forma descontextualizada, autoritária, sem considerar o saber e a liberdade do educando. Ao contrário, o educando deve ser incentivado a desenvolver sua autonomia, compreendendo seu lugar no mundo 
em busca de mudanças (Furim et al., 2019).

Assim, é preciso conhecer a realidade e demanda dos educandos antes de planejar e desenvolver práticas educativas em saúde na escola. O estudo em tela é relevante, uma vez que visa estimular práticas de educação em saúde nas escolas de forma participativa e contextualizada, favorecendo novos aprendizados, diálogos e vivências relativas à saúde escolar. Portanto, utilizou-se para nortear o estudo as seguintes perguntas: "Qual a concepção dos educandos sobre saúde?" e "O que e como gostariam de aprender sobre essa temática?" com os objetivos de compreender a concepção de discentes sobre prática educativa em saúde no ambiente escolar; e desenvolver ações educativas em saúde com estudantes do ensino fundamental.

\section{Metodologia}

Trata-se de um estudo qualitativo, desenvolvido na modalidade de pesquisa-ação. A pesquisa qualitativa tem como foco o significado e sentido que os participantes atribuem as coisas e a sua vida a partir da interpretação por parte dos pesquisadores sobre o fenômeno em estudo, possibilitando a descrição dos dados coletados (Pereira, Shitsuka, Parreira \& Shitsuka, 2018). A pesquisa-ação é uma estratégia de intervenção social, que oportuniza aos envolvidos discutirem e refletirem sobre seus próprios problemas em busca de soluções possíveis ou, pelo menos, esclarecer os problemas da situação em estudo, proporcionando a ampliação do nível de consciência quanto à situação problemática detectada, de modo a contribuírem com a reflexão e a transformação da realidade (Corrêa et al., 2018; Thiollent, 2011).

Para facilitar a descrição sobre cada uma das etapas da pesquisa-ação empreendida, optou-se por discuti-las por fases, com base em Thiollent (2011): exploratória, principal e ação. A fase exploratória permitiu construir as etapas de delimitação do tema de pesquisa, dos problemas, da teoria, do campo de observação ou desenvolvimento e da coleta de dados. Na fase principal, fez-se o planejamento da ação e na fase ação foi realizada a intervenção planejada com a avaliação das ações desenvolvidas.

Vale ressaltar a importância da delimitação do lugar da teoria na pesquisa-ação, visto que, para desenvolvê-la, é necessário estar articulada a uma situação problemática apoiada por um quadro de referência teórica. Dessa forma, a pesquisaação na área da saúde, estando pautada em preceitos Freireanos, direcionada para a melhoria das condições de vida, no contexto da pesquisa realizada com escolares, possibilitou uma intervenção conjunta nas temáticas e práticas educativas em saúde no ambiente escolar. Pois, trata-se de uma metodologia que propõe a partir da realidade identificada construir métodos adequados para captá-la e transformá-la. Utilizou-se a diretriz COREQ (Consolidated Criteria for Reporting Qualitative Research) para orientar a redação deste artigo (Tong et al., 2007).

A pesquisa adotou como referencial teórico-metodológico os conceitos de Paulo Freire, como dialogicidade, emancipação, liberdade, transformação, autonomia e contextualização, visto a necessidade de considerar fatores que contribuam para o protagonismo e a participação dos estudantes, promovendo o encontro entre sujeitos, fundamentado na dialogicidade e na construção coletiva do conhecimento (Fontana, 2018). Esse referencial tem aderência com a pesquisa, uma vez que a saúde na escola nasce das relações com o outro e que as mudanças das relações entre os sujeitos podem levar à transformação social. Assim, o diálogo se torna o centro da própria transformação, em que as pessoas em diálogo se transformam e transformam o mundo (Freire, 2012; Galli \& Braga, 2017).

\section{Procedimentos metodológicos}

O estudo foi desenvolvido em uma escola municipal, localizada no bairro do Caramujo, município de Niterói, Rio de Janeiro. A instituição foi escolhida por ofertar $6^{\circ}$ ano do ensino fundamental e por ser desde 2014 uma das escolas pactuadas no PSE do Município. A instituição atende às características de escolas prioritárias para participar do PSE, por exemplo, estar localizada próxima a uma unidade de saúde da família e possuir crianças beneficiárias do Programa Bolsa Família. 
Essa escola foi municipalizada há sete anos, mantendo o funcionamento de horário integral das 08 (oito) às $16 \mathrm{~h}$ (dezesseis), por estar localizada em uma comunidade com alto índice de violência. A escola possui apenas uma turma de $6^{\circ}$ ano, uma turma de aceleração do $5^{\circ}$ ano, duas turmas de $7^{\circ}$ ano e duas turmas de $8^{\circ}$ ano.

A turma de $6^{\circ}$ ano do ensino fundamental era composta por 24 educandos e todos participaram voluntariamente da pesquisa. A escolha pela turma do $6^{\circ}$ período se deu por ser uma série escolar geralmente acompanhada por transformações, novos sentimentos, atitudes psicossociais e conhecimento para os estudantes, visto que marca a transição da infância para a adolescência. Além disso, é acompanhada de diversas mudanças no perfil da estrutura curricular pelo início do ensino fundamental 2, caracterizando, portanto, uma nova etapa na vida escolar.

Incluíram-se no estudo educandos regularmente matriculados, cursando o $6^{\circ}$ ano do ensino fundamental, no período da produção dos dados. Os critérios de exclusão foram alunos que estivessem afastados da escola por algum motivo, assim como os que faltaram nos dias da produção dos dados.

Os participantes foram abordados por meio de um encontro de aproximação presencial na escola com apresentação das pesquisadoras e dos educandos, dos objetivos e razões da pesquisa e da atividade a ser desenvolvida, favorecendo a integração/relação entre educandos e pesquisadoras. Os estudantes foram convidados para participar da pesquisa e a levar um resumo explicativo com os termos para os responsáveis autorizarem. As autorizações foram entregues à Direção, que por sua vez repassou às pesquisadoras. Não houve recusa para participação e nenhuma desistência por parte dos discentes durante a pesquisa.

No que se refere à caracterização dos participantes, verificou-se que a idade dos 24 educandos participantes variou entre 11 e 15 anos; 15 (63,0\%) eram do sexo masculino; 18 (75,0\%) consideraram-se pardos; 13 (54,0\%) possuíam pais separados; 12 (50,0\%) residiam com suas mães; 14 (58\%) desconheciam o nível de instrução dos pais e 11 (46,0\%) a profissão. Em relação às condições de moradia, 22 (92,0\%) possuíam água encanada, $20(83,0 \%)$ saneamento básico, $18(75,0 \%)$ asfalto, $20(83,0 \%)$ coleta de lixo e $21(88,0 \%)$ chuveiro. Entretanto, todos (100,0\%) possuíam luz, vaso sanitário e geladeira. Ressaltase que um educando possuía diagnóstico médico de Diabetes Mellitus do tipo 1 e outro, diagnóstico de Hipertensão Arterial Sistêmica.

\section{Produção, organização dos dados e etapas do trabalho}

$\mathrm{O}$ estudo foi desenvolvido em três fases: exploratória, principal e ação. Na fase exploratória, o tema de pesquisa foi definido como a prática educativa em saúde no ambiente escolar. E o problema é a forma pontual, autoritária e tradicional de como essa prática educativa é desenvolvida, limitando-se à prevenção de doenças. A produção de dados foi realizada por meio da técnica World Café (Machado \& Passos, 2018), em dois encontros conduzidos por três pesquisadoras previamente treinadas, sendo uma pesquisadora/enfermeira/doutoranda e duas pesquisadoras/graduandas em Enfermagem/bolsistas de Iniciação Científica.

A fim de adequar as perguntas norteadoras do World Café e do questionário sociodemográfico, realizou-se um teste piloto com seis educandos da turma do $7^{\circ}$ ano, disponibilizados voluntariamente. Essa escolha foi baseada no fato de que a escola possuía apenas uma turma de $6^{\circ}$ ano e que o teste piloto deveria ocorrer com um grupo semelhante ao da pesquisa definitiva.

A produção dos dados aconteceu em novembro de 2016, na Sala de Artes da escola, com duração de aproximadamente 1h30min. Houve gravação em dispositivo de áudio e posterior transcrição. Anotações de campo foram feitas durante todo o processo. Fizeram-se necessários dois encontros para saturação dos dados (Minayo, 2014).

No $1^{\circ}$ encontro, as questões norteadoras foram: "O que é saúde para você?" e "O que gostaria de saber sobre saúde?". Nessa ocasião, entregou-se um questionário sociodemográfico para autopreenchimento visando caracterizar os estudantes. $\mathrm{O} 2^{\circ}$ 
encontro teve como questão norteadora: "Como vocês gostariam de aprender sobre questões de saúde?".

Como preconizado, estabeleceu-se um ambiente simulando um café, com três mesas, onde havia etiquetas com instruções sobre a atividade. Após o lançamento das questões norteadoras, solicitou-se que os participantes trocassem de mesa, levando as ideias-chave, temas e perguntas para outros participantes (Machado, et al., 2018). Em cada mesa, um estudante participou como "anfitrião", escolhido voluntariamente, com a função de estimular a participação e registrar discussões e sugestões. Ao final, houve apresentação dos grupos com cartazes confeccionados pelos educandos, fortalecendo, assim, diálogo e trocas.

$\mathrm{Na}$ fase principal, ou seja, na elaboração do planejamento das atividades a serem desenvolvidas também foi incluída a divulgação dos resultados. Essa divulgação foi feita em uma Roda de Conversa com os educandos, na qual as pesquisadoras apresentaram os resultados da coleta de dados e as propostas de ações. Assim, planejaram-se três práticas educativas em saúde grupais e lúdicas abordando os temas demandados: Atividade 1: dinâmica "Linha no chão: sim ou não", que tratou do desenvolvimento do corpo e alterações corporais, promovendo a percepção das mudanças corporais na adolescência; Atividade 2: dinâmica "Construção e propaganda sobre higiene corporal", que tratou do cuidado com a higiene corporal; e Atividade 3: dinâmica "Árvore de problemas e objetivos", que tratou da poluição e o meio ambiente, assim como a promoção do ambiente saudável e limpo.

Por último, a Fase Ação, compreendeu o desenvolvimento das 3 atividades planejadas e a avaliação das ações desenvolvidas. A atividade 1 aconteceu no primeiro encontro e as atividades 2 e 3 no segundo encontro. Para a atividade 1, utilizaram-se duas placas, "sim" e "não", coladas em dois lados da sala. Durante a dinâmica, fazia-se uma afirmação sobre desenvolvimento e/ou alteração corporal e os alunos se posicionavam na frente da placa "sim" se concordassem ou "não" caso não concordassem. Ao final de cada afirmação, realizou-se uma breve discussão com informações e questionamentos.

Para a atividade 2 e 3, a turma foi dividida voluntariamente em dois grupos. Na atividade 2 cada grupo recebeu um papel pardo. Um grupo desenhou a parte superior do corpo humano e o outro a parte inferior. Os grupos elaboraram uma propaganda para promover higiene e saúde corporal por meio de cartazes confeccionados com lápis coloridos, embalagens de diversos produtos de higiene e revistas para recortar e colar; em seguida, apresentaram seus produtos aos demais participantes, ressaltando a importância da manutenção da saúde por meio da higiene. Ao final, discutiram-se estudos de casos, com sugestão de estratégias para melhorar os problemas de saúde citados.

Para a atividade 3, cada um dos dois grupos ficou responsável por uma árvore e foi desenhado no quadro um demonstrativo da árvore. $\mathrm{Na}$ árvore de problemas, o tronco indicava o problema central, a poluição do meio ambiente; as folhas indicavam outros problemas derivados do central, como efeitos ou consequências; e as raízes, as causas ou fatores geradores. Já na árvore de objetivos, o tronco indicava o objetivo, o meio ambiente limpo; as folhas, os meios para alcançar; e nas raízes, as razões e a importância de se alcançar o objetivo. Ao final, discutiram-se algumas situações que correlacionavam questões saúde individual e meio ambiente.

A avaliação das práticas educativas realizadas foi feita por meio de notas avaliativas dadas pelos participantes após o término das atividades, a partir de papéis com números de 1 a 5 afixados em uma parede da sala. Os educandos se posicionaram na frente do número correspondente à nota da atividade de forma livre e forma imparcial, em que (1) corresponderia a uma atividade muito ruim; (2) ruim; (3) bom; (4) muito bom; e (5) excelente.

\section{Análise dos dados}

Os dados foram analisados por meio da Análise Temática, a qual inclui pré-análise; organização do material; leitura exploratória; mapeamento de grandes temas derivados dos dados e categorias que se destacaram; e interpretação dos resultados obtidos (Minayo, 2014). Não foi utilizado software. Emergiram duas categorias temáticas: Concepção de saúde: a visão dos 
estudantes; e Práticas educativas em saúde na escola: a demanda dos educandos. Tais categorias atendem à fase exploratória da pesquisa-ação e contribuíram para a concretização de uma ação planejada com os participantes. $\mathrm{Na} 1^{\text {a }}$ categoria, as unidades de registro foram formadas a partir de duas unidades de contexto, são elas: Saúde com foco no modelo biomédico; e Conceito amplo de saúde incipiente. E na $2^{\mathrm{a}}$ categoria: Demandas sobre saúde; e Ideias para a prática educativa em saúde.

\section{Aspectos éticos}

A pesquisa foi conduzida de acordo com os padrões éticos da Resolução no 466/12 (Brasil, 2013). O estudo foi aprovado pelo Comitê de Ética e Pesquisa da Universidade Federal Fluminense (UFF). Todos os responsáveis pelos educandos assinaram o Termo de Consentimento Livre e Esclarecido (TCLE) e estes, o Termo de Assentimento Livre e Esclarecido (TALE). Os discentes participantes foram identificados aleatoriamente pela letra E, inicial da palavra educando, seguida da sequência de 1 a 24, o que assegurou o anonimato dos participantes.

\section{Resultados}

$\mathrm{Na}$ fase exploratória da pesquisa-ação a partir da análise das entrevistas emergiram duas categorias temáticas: Concepção de saúde: a visão dos estudantes; e Práticas educativas em saúde na escola: a demanda dos educandos, as quais contribuíram para a fase ação da pesquisa.

\section{Concepção de saúde: a visão dos estudantes}

Para muitos participantes do estudo, a saúde se resume à ausência de doenças, acreditando que saúde e doença são fenômenos dicotômicos, demonstrando a sustentação do conceito antigo de saúde, focados no modelo higienista e biomédico. As falas abaixo revelam tal visão:

Aqui, está a ambulância representando a saúde. (E1)

É ir ao médico tomar vacina, tomar banho. (E2)

A saúde para mim é muito importante para ajudar a controlar as nossas doenças. (E12)

Em contrapartida, alguns educandos relacionam a saúde com hábitos de vida saudáveis e com ações relacionadas ao ato de descansar, brincar e jogar bola, conforme apontam os depoimentos a seguir:

Saúde para mim é comer muitas frutas, ter hábitos saudáveis. (E15)

É importante para cuidar da vida e da saúde que está em risco. (E22)

Saúde é se exercitar, comer frutas, alimentos saudáveis e cuidar do nosso ambiente. (E11)

São crianças brincando, jogando bola e cuidando do nosso corpo. (E4)

\section{Práticas educativas em saúde na escola: a demanda dos educandos}

Todos os participantes informaram que gostariam de aprender diferentes aspectos sobre saúde. Os depoimentos abaixo ilustram esses desejos:

Eu queria saber sobre o desenvolvimento do corpo e porque as meninas sentem cólicas e menstruam. (E14)

Gostaríamos de saber como podemos lavar as mãos e escovar os dentes. (E4)

Qual a importância de se exercitar? (E5)

Sobre o desmatamento, pois estão acabando com as árvores. O que acontece com a gente por causa dessa poluição do ar e diminuição das árvores? (E3)

Esse desenho é sobre o lixo, quero saber sobre isso. (E6)

A água parada nos pneus e os mosquitos, as doenças do Zika Vírus. (E10)

Como se previne, transmite e os sintomas. (E1) 
Com relação ao interesse dos educandos pelo meio ambiente e impactos ambientais na saúde da população, vale ressaltar suas vivências, visto que a comunidade onde a escola está localizada deposita o lixo em um "barranco" diretamente no terreno da escola, causando repercussões em toda a comunidade.

Quando perguntados sobre como gostariam de aprender temas sobre saúde, a maioria dos educandos se referiu a atividades lúdicas e participativas, tais como:

Fazendo aula com jogos de tabuleiro e vídeos. Aula de gastronomia. (E9)

Aula de música, aula de dança, com muitas dinâmicas. Através de brincadeiras. (E14)

Jogos diferentes. Aula fora da escola. (E7)

Pesquisa na internet, ouvindo palestras, reportagens, vendo filmes etc.(E11)

Lendo livros. (E15)

Vale ressaltar que os participantes que vivem com Doenças Crônicas Não Transmissíveis, como Hipertensão e Diabetes, demonstraram interesse em conhecer mais sobre essas doenças:

Queria saber sobre Pressão Alta. (E5)

Gostaria de aprender sobre Diabetes. (E14)

Quanto a fase ação da pesquisa, esta foi realizada a partir dos achados acima, os quais permitiram a realização de ações planejadas na fase principal, ou seja, na elaboração do planejamento das atividades a serem desenvolvidas a partir da demanda dos participantes. Nas três práticas educativas desenvolvidas com os participantes do estudo na fase ação, percebeuse que como os temas e abordagens utilizadas partiram das demandas dos educandos, estes se sentiram mais motivados e interessados na discussão.

Em relação à avaliação das práticas educativas em saúde realizadas durante a Atividade 1: dinâmica "Linha no chão: sim ou não", $22(92,0 \%)$ educandos consideraram a prática educativa excelente e dois $(8,0 \%)$ como muito bom. Para a Atividade 2: dinâmica "Construção e propaganda sobre higiene corporal", 23 (96,0\%) educandos consideraram a prática educativa excelente e um (4,0\%) como muito bom. Já para a Atividade 3: dinâmica “Árvore de problemas e objetivos", 20 $(83,0 \%)$ educandos consideraram excelente e quatro $(17,0 \%)$ como muito bom.

\section{Discussão}

Nas práticas educativas em saúde é predominante o modelo que privilegia ações curativas e centraliza-se no atendimento médico, segundo a visão biológica do processo saúde-doença, que condiciona à ações que visam modificar práticas dos indivíduos consideradas inadequadas pelos profissionais (Ramos, Araruna, Lima, Santana \& Tanaka, 2018). Corroborando com essa realidade, em um estudo com adolescentes, 69\% dos alunos afirmaram que ter saúde significa estar bem, enquanto para $31 \%$ é estar sem doença (Silva, Mendonça, Bastos \& Leite, 2017). Portanto, a vivência do adolescente acerca da saúde escolar remete a um número expressivo de discursos com caráter higienista (Faial, Silva, Pereira \& Faial, 2019). Este cenário permite a manutenção de uma abordagem normativa e comportamentalista, sendo entendida muitas vezes como consequência histórica de como a área da saúde adentrou à escola ao longo do tempo. Compreender este panorama e propor outras iniciativas é necessário para que se possa superar antigos paradigmas em busca de novas concepções, práticas e metodologias, nas quais a prioridade e os alvos sejam a construção de conhecimentos e o desenvolvimento da autonomia para a tomada de decisões (Venturi \& Mohr, 2021).

Contudo, há educandos relacionando saúde ao cuidado com ambiente e com o corpo, valorizando práticas de promoção da saúde (Faial et al., 2018; Silva et al., 2018). Quanto ao cuidado com o meio ambiente, esse fato reforça a 
importância das interações do ser humano com a natureza. Assim, a doença e a saúde são entendidas como um processo associado à interação de diferentes fatores. Em um estudo com adolescentes, estes consideraram importante educar-se perante as necessidades e cuidados ambientais (Brito et al., 2016). No que se refere ao cuidado com o corpo, conhecer e entender sobre as mudanças corporais no processo de adolescer é uma temática relevante para ser discutida com esse grupo populacional, proporcionando aprendizados e contribuindo na construção saudável da autoimagem, autocuidado e autonomia (Sousa et al., 2016). Assim, ao integrar esses itens ao cuidado, ampliam-se as possibilidades de um conceito de saúde mais amplo e de promoção da saúde dos escolares.

Destarte, conceber saúde de forma abrangente implica em ampliar as possibilidades interativas para além da teoria e prática por meio de debates e discussões que fortaleçam e divulguem esse conceito (Oliveira et al., 2015). É primordial o desenvolvimento do processo educativo em que a comunidade escolar torna-se central, com foco na produção conjunta de saber, na transformação e autonomia. Para Paulo Freire, a educação deve ter como referência a prática da liberdade, ampliando o acesso aos conhecimentos acumulados historicamente, instigando os estudantes à curiosidade, à investigação dos problemas sociais, e ao engajamento no mundo. Assim, o estudante se apropria das condições necessárias para tomar consciência de si, da sua história no mundo, e posicionar-se criticamente (Machado et al., 2021). Países latino-americanos reconhecem que as ações educativas em saúde geram conhecimento e capacitam grupos e/ou comunidades acerca de diversos temas, sendo responsável em contribuir com o refinamento do conhecimento (Casemiro, et al., 2014).

De tal modo, o conceito de saúde e as ações educativas desenvolvidas necessitam de adaptações para atender às demandas sociais. Em um estudo, participantes manifestaram sobre o desinteresse nas ações educativas, as quais eram ministradas apenas na forma de aula e enfatizaram práticas educativas dialógicas e lúdicas (Ramos, et al., 2018; Rodrigues et al., 2015). Destaca-se que na atualidade, são necessárias reformulações com inovações e mudanças, aproximando os conteúdos curriculares das necessidades e demandas dos alunos por meio de metodologias ativas. Estratégias inovadoras para se trabalhar os conteúdos disciplinares e a utilização de atividades interativas com o educando, como experiências práticas, vivências grupais, rodas de conversa, modelos dialógicos de aprendizagem, trocas de experiências e utilização da ludicidade, proporcionam mais sentido e aproximação no processo de aprendizagem dos educandos (Masson et al., 2020).

A partir dessas práticas contribui-se para uma educação emancipadora com a formação de espaços coletivos de diálogo, fontes de prazer, reforçando que o ato de brincar envolve diversos aspectos, constituindo-se como um importante elemento no processo de aprendizagem e desenvolvimento da autonomia e da responsabilidade dos indivíduos no cuidado com a saúde. Estratégias lúdicas facilitam a participação ativa dos envolvidos, a promoção de criatividade, o pensamento críticoreflexivo e a expressão da singularidade do educando, promovendo o seu empoderamento como sujeito protagonista de suas ações, ativo e autônomo na superação das dificuldades (Alencastro et al., 2020).

Assim, o processo de ação e reflexão de Freire na prática educativa inspiram novos fazeres e novos compromissos para que se possa atingir práticas transformadoras (Batista \& Fagundes, 2021). Um estudo refere que segundo as ideias de Paulo Freire e aplicando-as sobre a educação e a liberdade na promoção da saúde escolar, para que os estudantes realizem uma leitura crítica do mundo e constituam as condições apropriadas para agir sobre a realidade desse mundo, é fundamental a apropriação dos conhecimentos referentes à promoção da saúde escolar, como parte do legado humano (Machado, et al., 2021).

Ressalta-se que as ações devem ser mediatizadas pela realidade, estimulando a construção do conhecimento no desenvolvimento da ação-reflexão-ação. Nesse sentido, destaca-se que os educandos portadores de Hipertensão e Diabetes, demonstraram interesse em conhecer mais sobre tais doenças. Confirmando essa realidade, um estudo realizado com adolescentes com Doenças Crônicas não Transmissíveis demonstrou que para eles é imprescindível o conhecimento do tratamento, sinais e sintomas e autocuidado (Costa \& Santos, 2016). Esse fato reforça a ideia de Freire quanto à valorização do contexto dos educandos, visto que uma educação distanciada da experiência existencial, na qual os conteúdos são retalhos da 
realidade, desconectados da totalidade, não tem significação para o educando (Furim, et al., 2019). Então, as práticas educativas em saúde devem ser capazes de fortalecer os participantes no processo e suas necessidades.

Sustentando esse achado, há relatos na literatura reforçando a pouca discussão com escolares sobre questões de saúde inerentes ao contexto em que estão inseridos, salientando a importância da interdisciplinaridade no espaço escolar e a construção do saber de modo colaborativo, extensivo à família e comunidade local (Ribeiro et al., 2017). Assim, a participação ativa dos envolvidos, a promoção de criatividade, o pensamento crítico-reflexivo e a expressão da singularidade do adolescente promovem o seu empoderamento como sujeito protagonista de suas ações, mais ativo e autônomo na superação de suas dificuldades (Alencastro, et al., 2020).

Diversos aspectos sobre saúde escolar precisam ser aprofundados e abordados continuamente, uma vez que ainda há equívocos nos conceitos, dúvidas e potencialidades. Fortalecendo essa realidade, em um estudo com escolares, a maioria identificou apenas a verificação do peso e da altura como práticas em saúde realizadas em sua escola e 27,9\% dos escolares não consideram existir um trabalho voltado para a promoção da saúde nas escolas, seja por falta de esclarecimento das atividades desenvolvidas na escola pelo PSE, seja porque o escolar não foi capaz de identificar que as atividades promovidas pelo PSE são para promoção de sua saúde (Carvalho et al., 2020). Tal fato deve ser visto com preocupação, uma vez que as atividades não estão ultrapassando a ação pontual e, com isso, torna-se difícil provocar mudanças na prática.

Nesse contexto, é necessário atentar que é a partir da visão de promoção da saúde dos profissionais de saúde e educação que se originam as ações de promoção da saúde no ambiente escolar. Logo, o planejamento incipiente incentiva ações pontuais, descontextualizadas, focadas na prevenção de doenças e no modelo biomédico. Assim, o entendimento de promoção da saúde implica mudanças profundas na forma de articular, planejar e utilizar o conhecimento na formulação e operacionalização das ações educativas em saúde na escola (Luquez et al., 2021). De tal modo, é necessário pensar em práticas educativas em saúde no ambiente escolar de forma contínua, intersetorial e contextualizada, tendo em vista que as escolas são ambientes dinamizadores da saúde. Os profissionais da saúde e da educação devem estar atentos para a identificação das necessidades locais, com vistas ao planejamento e execução de práticas que contribuam na construção do pensamento crítico e reorientação de atitudes e práticas.

Com isso, oportuniza-se ao educando relacionar o tema abordado ao conhecimento prévio, associando os saberes com conhecimentos científicos e práticos apreendidos durante a intervenção educativa, construindo conhecimento de uma maneira mais real e dinâmica para os escolares (Bragagnollo et al., 2019). Assim, a prática educativa participativa em saúde desenvolvida nas escolas poderá atuar como uma ponte entre as práticas sociais da educação e da saúde. Partindo dessa ideia, as três práticas educativas desenvolvidas na fase ação contribuíram de maneira ativa para a promoção em saúde, uma vez que, ao planejar as ações, as pesquisadoras avaliaram e empregaram situações cotidianas e demandadas pelos participantes.

\section{Considerações Finais}

Os objetivos do estudo foram atingidos, uma vez que foi possível compreender a concepção dos discentes sobre a prática educativa e desenvolver ações educativas em saúde com esse grupo específico. Os participantes correlacionaram saúde com prevenção de doenças e desejaram que as práticas educativas fossem lúdicas e dinâmicas. As demandas temáticas versaram principalmente sobre o meio ambiente, desenvolvimento e higiene do corpo e estão diretamente relacionadas ao contexto e à faixa etária em que se encontram. Na fase de ação, os educandos avaliaram positivamente as práticas educativas desenvolvidas participativamente, as quais se mostraram como um excelente recurso didático e estratégico para ações de promoção da saúde com base na demanda e contexto dos educandos para o fazer saúde. Assim, é necessário que as áreas de educação e saúde, enquanto práticas sociais, contribuam para a produção do conhecimento científico no campo da promoção 
da saúde escolar e se apropriem de novas teorias e práticas para que, assim, (re)construam um modelo de atenção à saúde dialógico de saberes com escolares adolescentes atuando como um potente instrumento para a promoção da saúde na escola.

Este estudo contribuirá para o ensino, a pesquisa e assistência na área da prática educativa em saúde com escolares, à medida que amplia o conhecimento das demandas educacionais em saúde, favorecendo a utilização de estratégias que levam em conta as necessidades e conhecimentos prévios dos educandos, possibilitando mudanças nas práticas educativas em saúde com vistas a melhorias na qualidade de vida, beneficiando participantes, família e comunidade escolar. Isso beneficia não só a informação, mas também a reflexão, a crítica, a sensibilização e reorientação do fazer saúde na escola, apoiado na escuta do estudante, privilegiando o protagonismo e o desenvolvimento da ação-reflexão-ação. Destaca-se ainda que a experiência pode contribuir para a ampliação dos cenários de atuação do profissional enfermeiro em outras áreas da saúde envolvidas, possibilitando a instrumentalização de discentes da graduação e pós-graduação para o adequado cuidado ao adolescente. Pois, destaca-se a figura do profissional de saúde como agente colaborador, orientador e mediador do processo de desenvolvimento de habilidades e responsabilidades a fim de facilitar a prestação e multiplicação do cuidado.

O estudo teve como limitação o fato de ter sido desenvolvido apenas com uma turma de alunos do $6^{\circ}$ ano do ensino fundamental de uma escola pública. Assim, apesar de os achados revelarem significados atribuídos pelos educandos acerca da saúde escolar, eles se resumem às especificidades do cenário da pesquisa.

Nesse sentido, é indispensável que ocorram trabalhos futuros envolvendo a presente temática para a ampliação das evidências e solução do problema social abordado. Vale ressaltar que a utilização da pesquisa-ação pode incrementar e facilitar o planejamento e execução de práticas de promoção da saúde no espaço escolar. Assim, fazem-se necessários novos estudos em outras realidades com ampliação do público participante para que juntamente com o conhecimento obtido neste estudo, possam potencializar o entendimento do contexto e da demanda dos educandos e então, mudanças nas práticas educativas em saúde na escola por meio de práticas lúdicas, dinâmicas, contínuas e contextualizadas.

\section{Referências}

Alencastro, L. C. S., Silva, J. L., Komatsu, A. V., Bernardino, F. B. S., Mello, F. C. M., \& Silva, M. A. I. (2020). Theater of the Oppressed and bullying: nursing performance in school adolescente health. Rev Bras Enferm,, 73(1):e20170910. http://dx.doi.org/10.1590/0034-7167-2017-0910

Batista, A. F., \& Fagundes, M. (2021). O pensamento de Paulo Freire: gênese e consolidação da educação popular no Brasil. Research, Society and Development, 10(15), e437101523278. http://dx.doi.org/10.33448/rsd-v10i15.23278

Bragagnollo, G. R., Santos, T. S., Fonseca, R. E. P., Acrani, M., Castelo Branco, M.Z.P., \& Ferreira, B.R. (2019). Playful education al intervention with school children on intestinal parasitosis. Rev. Bras. Enferm., 72(5), 1203-10. http://dx.doi.org/10.1590/0034-7167-2017-0551

Brasil. Conselho Nacional de Saúde. (2013). Resolução no 466, de 12 de dezembro de 2012 [Internet]. Diário Oficial da União: República Federativa do Brasil; Seção 1: p. 59. Recuperado em 8 de junho, 2021, de: http://conselho.saude.gov.br/resolucoes/2012/Reso466.pdf

Brito, V. L. T, Moraes, L. A., Machado, R. R. B., \& Araújo, M. F. V. (2016). Importância da educação ambiental e meio ambiente na escola: uma percepção da realidade na escola municipal Comendador Cortez em Parnaíba (PI). Rev. Bras. Educ. Ambient., 11(2), 22-42. https://doi.org/10.34024/revbea.2016.v11.2139

Carvalho, K. N., Zanin, L., \& Flório, F. M. (2020). Percepção de escolares e enfermeiros quanto às práticas educativas do programa saúde na escola. Rev. Bras. Med. Fam. Comunidade, 15(42), 2325. https://doi.org/10.5712/rbmfc15(42)2325

Casemiro, J. P., Fonseca, A. B. C., \& Secco, F. V. M. (2014). Promoting health in school: reflections based on a review of school health in latin America. Cienc. Saúde Coletiva, 19(3), 829-40. https://doi.org/10.1590/1413-81232014193.00442013

Cavalcanti, P. B., Lucena, C. M. F., \& Lucena, P. L. C. (2015). Programa Saúde na Escola: interpelações sobre ações de educação e saúde no Brasil. Textos \& Contextos, 14(2), 387-402. https://doi.org/10.15448/1677-9509.2015.2.21728

Chiari, A. P. G., Ferreira, R. C., Akerman, M., Amaral, J. H. L., Machado, K. M., \& Senna, M. I. B. (2018). Rede intersetorial do Programa Saúde na Escola: sujeitos, percepções e práticas. Cad. Saúde Pública, 34(5):e00104217. https://doi.org/10.1590/0102-311X00104217

Corrêa, G. C. G., Campos, I. C. P., \& Almagro, R. C. (2021). Pesquisa - Ação: uma abordagem prática de pesquisa qualitativa. Ensaios Pedagógicos, 2(1), 6272. Recuperado de: http://www.ensaiospedagogicos.ufscar.br/index.php/ENP/article/view/60/89

Costa, J. S., \& Santos, M. L. S. C. (2016). Group of adolescents hospitalized with non-communicable chronic disease as a technology of nursing care. Rev. Enferm. UFPE online, 10(2), 508-14. https://10.5205/reuol.8557-74661-1-SM1002201617 
Faial, L. C. M., Silva, R. M. C. R. A., Pereira, E. R., \& Faial, C. S. G. (2019). Health in the school: perceptions of being adolescent. Rev. Bras. Enferm., 72(4), 964-72. http://dx.doi.org/10.1590/0034-7167-2018-0433

Faial, L. C. M., Silva, R. M. C. R. A., Pereira, E. R., Faial, C. S. G., \& Deus, V. A. H. (2018). Perceptions of adolescentes on health at school in the light of a Merleau pontian phenomenology. Rev.Min. Enferm., 22:e-1136. http://dx.doi.org/10.5935/1415-2762.20180065

Faial, L. C. M., Silva, R. M. C. R. A., Pereira, E. R., Refrande, S. M., \& Faial, C. S. G. (2016). The school as na environment for health promotion during adolescence: literature review. Rev. Pro-Uni, 7(2), 22-9. Recuperado de: http://editora.universidadedevassouras.edu.br/index.php/RPU/article/view/344/525

Fontana, R. T. (2018). O processo de educação em saúde para além do hegemônico na prática docente. Contexto Educ., 106(33, :21791309.https://doi.org/10.21527/2179-1309.2018.106.84-98

Freire, P. (2012). Pedagogia da esperança: um reencontro com a pedagogia do oprimido. 26. ed. 336 p. Rio de Janeiro: Paz \& Terra.

Furim, M. M. F. S., Castorino, A., \& Seluchinesk, R. D. R. (2019). Leitura do mundo e leitura da palavra em Paulo Freire. Revista Humanidades e Inovação, 6(10), 224-34. Recuperado de: https://revista.unitins.br/index.php/humanidadeseinovacao/issue/view/53

Galli, E. F., \& Braga, F. M. (2017). O diálogo em Paulo Freire: concepções e avanços para transformação social. Quaestio - Revista de Estudos em Educação. 19(1), 161-180. https://doi.org/10.22483/2177-5796.2017v19n1p161-180

Luquez, T. M. S., Saboia, V. M., Meireles, A. C. M., Moura, C. F., Ribeiro, C. R. B., \& Silveira, A. L. D. (2021). Ações de promoção da saúde nas escolas brasileiras: uma revisão integrativa. Research, Society and Development, 10(1), e57110112112. http://dx.doi.org/10.33448/rsd-v10i1.12112

Luquez, T. M. S., Saboia, V. M., Silva, T. M. L., Teixeira, G. O. M., Ribeiro, C. R. B., \& Daher, D. V. (2019). Escola como ambiente de fazer saúde: estudo participativo com educadores. Online Braz. J. Nurs., 18(1), 62-73. https://doi.org/10.17665/1676-4285.20196273

Machado, V. A., Pinheiro, R., \& Miguez, S. F. (2021). Educação e liberdade na promoção da saúde escolar: perspectivas compreensivas sobre a ação política como potência nas comunidades escolares. Interface (Botucatu), 25:e200035. https://doi.org/10.1590/interface.200035

Machado, M. P. M., \& Passos, M. F. D. (2018). O uso do World Café como método de pesquisa junto às equipes de saúde. Rev. Bras. Promoç. Saúde. 31, 110. https://doi.org/10.5020/18061230.2018.8647

Masson, L. N., Silva, M. A. I., Andrade, L. S., Gonçalves, M. F. C., \& Santos, B. D. (2020). A educação em saúde crítica como ferramenta para o empoderamento de adolescentes escolares frente suas vulnerabilidades em saúde. REME - Rev. Min. Enferm., 24:e-1294. http://dx.doi.org/10.5935/14152762.20200023

Minayo, M. C. S. (2014). O desafio do conhecimento: pesquisa qualitativa em saúde. 416 p. São Paulo: Hucitec.

Oliveira, V. J. M., Martins, I. R., \& Bracht, V. (2015). Projetos e práticas em educação para a saúde na educação física escolar: possibilidades! Rev. Educ. Fis., 2(26), 243-55. http://dx.doi.org/10.4025/reveducfis.v26i2.25600

Pereira, A. S., Shitsuka, D. M., Parreira, F. J., \& Shitsuka, R. (2018). Metodologia da pesquisa científica. 1. ed., e-book. Santa Maria, Rio Grande do Sul: UFSM, NTE. Recuperado em: https://repositorio.ufsm.br/bitstream/handle/1/15824/Lic_Computacao_Metodologia-Pesquisa-Cientifica.pdf?sequence=1

Ramos, C. F. V., Araruna, R. C., Lima, C. M. F., Santana, C. L. A., \& Tanaka, L. H. (2018). Education practices: research-action with nurses of Family Health Strategy. Rev. Bras. Enferm. 71(3), 1144-51. http://dx.doi.org/10.1590/0034-7167-2017-0284

Ribeiro, C. R. B., Saboia, V. M., Daher, D. V., \& Koopmans, F. F. (2017). Environmental and health education for schoolchildren: other directions for nursing. Rev. Enferm. UERJ. 25:e26182. http://dx.doi.org/10.12957/reuerj.2017.26182

Rodrigues, D. A., Sampaio, T. B., Leça, A. C. M. M., Almeida, M. A., Macêdo, I. S. V., \& Mota, C. A. X. (2015). Práticas educativas em saúde: o lúdico ensinando saúde para a vida. Rev. Ciênc. Saúde Nova Esperança, 13(1), 84-89. https://doi.org/10.17695/revcsnevol13n1p91\%20-\%2096

Silva, J. S., Mendonça, W. F., Bastos, L. L. A. G., \& Leite, S. T. (2017). O conceito de saúde e de hábitos saudáveis em adolescentes escolares. Pensar Prát., 20(4). https://doi.org/10.5216/rpp.v20i4.43918

Silva, K. V. L. G., Goncalves, G. A. A., Santos, S. B., Machado, M. F. A. S., Rebouças, C. B. A., Silva, V. M., \& Ximenes, L. B. (2018). Training of adolescente multipliers from the perspective of health promotion core competencies. Rev. Bras. Enferm., 71(1), 89-96. http://dx.doi.org/10.1590/0034-71672016-0532

Sousa, A. R., Araújo, J. L., \& Nascimento, E. G. C. (2016). Imagem corporal e percepção dos adolescentes. Adolescência e Saúde, 13(4), 104-117. http://dx.doi.org/10.33448/rsd-v9i7.4908

Thiollent, M. (2011). Metodologia da pesquisa-ação. $18^{a}$ ed. 136 p. São Paulo: Cortez.

Tong A, Sainsbury P, Craig J. (2007). Consolidated criteria for reporting qualitative research (COREQ): a 32 -item checklist for interviews and focus groups. Int. J. Qual. Health Care, 19(6), 349-357. https://doi.org/10.1093/intqhc/mzm042

Venturi, T., \& Mohr, A. (2021). Panorama e Análise de Períodos e Abordagens da Educação em Saúde no Contexto Escolar Brasileiro. Pesquisa em Educação em Ciências, 23:e33376. http://dx.doi.org/10.1590/1983-21172021230121 